\title{
Role of Customer in Marketing and Development (RCMD) - a literature review
}

\author{
Ehsanullah Oria*, Mirwan Surya Perdhana \\ Department of Master of Management, Faculty of Economics and Business, \\ Diponegoro University, Semarang, Indonesia
}

\begin{abstract}
Article History
Received : 8 February 2021

Revised : 2 January 2021

Accepted : 21 August 2021

Published : 27 August 2021
\end{abstract}

Keywords:

RCMD, customers' participation, Firms' point of view, marketing strategy.

${ }^{*}$ Corresponding author:

oria.ehsan@gmail.com

DOI:

10.20885/AMBR.vol1.iss2.art3

\begin{abstract}
The purpose of this article is to review empirical researches on role of customer in marketing and development (RCMD) and betterment of the firm's performance and pave the way for future researches. This article is a cumulative literature review of empirical articles on (RCMD). In previous empirical studies two units of analysis has been conducted (individual and firm unit) which includes two viewpoints: The customers' viewpoint and the firms' viewpoint. The customers' viewpoint that consider RCMD issues from customer perspectives and stresses on practices of customers in marketing and development. The company's viewpoint looks at RCMD issues from firms' perspectives and analyzes company's action of including customers and how RCMD may influence firm's performance. During the investigation it was found that RCMD comprises of different streams of literature that follow various conventions and remain very detached from one another. However, there are some common themes between these two streams of researches. For instance, customer knowledge and experience has all seems to be vital for RCMD from the two points of view, learning capacities of a customer and of a firm have both been discovered to be exceptionally important for RCMD. It was also found that significantly less exploration is done from the firm's viewpoint to understand what drives firms to receive RCMD and what prepares them to effectively preform it. Ultimately, there was absence of hypothetical improvement in all subareas. This article goes beyond existing researches by uniting various streams of studies, evaluating key differences related to the concept and findings on antecedents and outcomes of RCMD. This article suggest that future studies ought to embrace a consistent and predictable conceptualization of RCMD and restrain using wide terms.
\end{abstract}

\section{Introduction}

Recently, we saw a flood of new practices that are changing the position of customers in development. Traditionally acting as purchasers and users of merchandise and ventures, customers are progressively taking on new functions of effectively taking an interest in firms' advancement endeavors or making new items all alone (Hoyer, et al. 2010; Von Hippel and Katz, 2002). These practices are changing the worldview of advancement and turning into the new frontier of competitive advantage (Ramaswamy and Prahalad, 2000).

Generally, an inner action of firms' development is presently growing past organizational limits to include customer exercises and activities that are not under firms' immediate control. This move in advancement practice gives firms incredible chances, however it additionally makes difficulties of dealing with the related management and strategic change (Cui and Wu, 2016). An advanced academic research is dedicated for the understanding of customer inclusion in marketing and development of the business performance, customers' support in developing experience to make a new product or to give contributions for the improvement of existing products. 
There has been an expanding number of articles distributed on this theme in both development, innovation and advertising journals. However, beside the quick development of this research, existing literature remains profoundly differing, lacking a common understanding of what constitute customers' involvement in innovation and marketing and its hypothetical underpinnings. There is a huge number of conceptualizations of customer involvement in marketing and innovation, and given that it incorporates a wide scope, numerous examinations look at explicit issues inside different observational settings that may not offer generalizable hypothetical implications. Critically, in spite of the fact that it is believed that customers' involvement in marketing and innovation can assist firms with bettering understanding of customers' needs and rouse imagination, its actually commitment to development performance stays unclear, as appeared in the highly conflicting empirical findings (Chang and Taylor, 2016).

Numerous researchers have called attention to the dangers and difficulties of drawing in customer in development (Hoyer, et al., 2010), however research has offered minimal valuable experiences on how firms may better manage them. To better understand how firms can viably make an interpretation of customer contributions to fruitful advancement, a strategic perspective is particularly valuable as it permits researchers to look at the organizational framework and capacities needed to implement the role of customers in marking and innovation as well as its longterm impact on firm's overall strategy. In this part, we explore a review of existing empirical research on customer role in innovation and marketing and offer suggestions for future studies in this area.

This article goes beyond existing researches by uniting various streams of studies, evaluating key differences related to the concept and findings on antecedents and outcomes of roles of customer in marketing and development. Thus, this article attempts to offer a more hypothetical point of view on the role of customers in marketing and development. Besides, we take a vital point of view that centers around how firms may better manage and profit by involving customers, for example, how to settle on choices of receiving this role, how to assemble abilities to implement customer roles, and the long-run effect of the role of customer on firm strategy. This article also aims to point out future research questions and related hypothesis from the marketing strategy articles that can provide further assessments in this regard.

\section{Literature Review and Hypothetical Framework}

Studies that take the customer's point of view will in general utilize individual customers as a unit of analysis and clarify individual contrasts among customers, e.g., why a few customers are more willing or ready to participate in RCMD; researches from the company's viewpoint use tasks and projects, products, or firms as the unit of study and in this way don't clarify individual customer contrasts. While the customer's viewpoint centers on different customer credits, the firm's point of view is more inspired by qualities of tasks and projects, managers, and the firm that can anticipate RCMD exercises. When studies concentrate from the company's viewpoint often consider customer characteristics (Athaide and Zhang, 2011; Mahr, et al. 2014), they center around the general customer qualities that a firm face in the market and clarify differences among projects, products, or firms instead of individual customers, and they accumulate data on customer characteristics from firms instead of directly from customers. Essentially, with respect to outcomes of RCMD, research from the customer's viewpoint is interested on understand in how RCMD impacts customers' practices and activities, while from the company's viewpoint intends to understand RCMD's effect on firm performance. In this article we look at these two viewpoints of researches independently.

\section{Studies from Customer's Viewpoint}

Small companies taking the customers' point of view are customer-focused. That means they keep the customer in mind when developing their products and services. Plenty of studies have inspected the qualities and behaviors of customers that take part in development. These researches are led in the B-to-C pretext and utilize individual customers as the unit of examination. They look at 
customers' psychological cycles that inspire them to develop, individual credits that impact their capacity to improve, also how involvement in advancement impacts their psychological state, attitude, and practices toward a product or Brand. Therefore, numerous examinations take a behavioral point of view and focuses customers' individual attributes which will help to understand individual contrasts and their antecedents from customer's view point.

\section{Antecedents from The Customer's Viewpoint}

Numerous examinations take a behavioral point of view and focuses customers' individual attributes, for instance, character qualities (Fuller, et al. 2008), lead-client attributes (Franke, et al. 2006), feelings and emotions, for example, brand trust and brand distinguishing identification (Fuller, et al. 2008), and saw bane-attacks of interest (Nambisan and Baron, 2009). These attributes and characteristics help understand individual contrasts among customers, i.e., why a few customers are more engaged and connected than others. recent investigations are going ahead of individual characteristics to consider factors, for example, a customer's situation in the social network and local resource support and uphold (Franke, et al. 2006), and saw credits of the inventive stage (Balka, et al. 2014; Nambisan and Baron, 2009). However still conducted at customer level, these examinations acquire factors that might be sensible by the firm, for example, resource support and advancement platform.

Another significant question analyzed from the customer's viewpoint is the factor that variables impact a customer's capacity to contribute to advancement and development. This surge of research inspects what kinds of customers are more willing to submit top high quality thoughts, different ideas, or thoughts that are implemented by the firm. These investigations likewise focus on individual credits, for example, knowledge and experience. Latest studies begin to inspect how customers' actual behaviors, for example, intensity and variety of planned activities, presence in the network (Jensen, et al. 2014), and past participation can impact their capacities to contribute great development. Like researches on the inspiration of RCMD, several examinations have gone beyond individual qualities and behaviors to consider factors that might be sensible by the firm, for example, asset or resource support or uphold (Franke, et al. 2006).

All and all, research from the customer's viewpoint gives helpful experiences on customers' mental and psychological cycles and practice or behaviors that impact their commitment in marketing and advancement, and it offers significant implications for recognizing customers that are more willing and ready to enhance and potentially motivate them to engage. These investigations don't directly address the issue of how firms may implement their strategies or systems of distinguishing and motivating customers. Given perceived and recognized challenges and obstacles of managing and overseeing RCMD (Hoyer, et al. 2010), the understandings of customer practices should be converted into successful incentive structures, process, and emotionally supportive networks that permit firms to connect with the correct kinds of customers and effectively deal with their commitment. The ongoing researches that explored customers' view of advancement and development stages consider parts of RCMD that are reasonable by firms and accordingly offer more straightforward implications for firm moves. As studies on RCMD develops, these investigations feature the need to collaborate examination on customer behaviors with the firm's point of view that thinks about the organizational processes and strategies of RCMD.

\section{Consequences of the Customer's viewpoint}

As to the results of RCMD, research from the customer's viewpoint targets to understand how commitment in development impacts customers' emotions feelings, perceptions, practice and behaviors. This types of studies also focuses on individual consumers in the B-to- $\mathrm{C}$ setting. customers' support in development activities has been found to make sentiments and feelings of achievement (Franke, et al. 2010) and strengthening (Dahl, et al. 2015), impact product observations (Fuchs, et al. 2013), and further influence product use, for example, buying intentions and product inclination (Dahl, et al. 2015), and eagerness to pay (Schreier, et al. 2012). A few investigations find that the effect of RCMD on customer recognitions goes beyond particular 
products. Clients may see firms that embrace RCMD methodologies to be more customer situated (Fuchs, et al. 2013) and have stronger advancement capacities and they may create stronger distinguishing identifications (Dahl, et al. 2015) and more positive attitude toward these organizations.

These findings obviously, show the advantages of RCMD for the customers just as for the firm, for instance, improved customer recognitions, inclinations, and purchase intention. They recommend that organizations need to proactively manage RCMD to encourage the improvement of these positive results among partaking customers and to make an interpretation of these results into better development performance. These examinations, nonetheless, don't straightforwardly connect RCMD to firm performance or offer insights on the best way to manage RCMD adequately to create values for the firm.

\section{Studies from the Firm's viewpoint}

Studies from the firm's viewpoint stresses on firms' activities of including customers in marketing and development and how RCMD may influence advancement performance. Researches in this regard have been conducted in both $\mathrm{B}$ to $\mathrm{B}$ and $\mathrm{B}$ to $\mathrm{C}$ regards and regularly utilize a NPD (new product development) Project as the unit of investigation. In spite of the fact that customer qualities are sometimes considered, they are treated as a market trait confronting a NPD project without thinking about individual contrasts among customers.

\section{Antecedents from the firm's viewpoint}

To know what drives firms' reception of RCMD, a few research focus on the idea of NPD (new item improvement) projects, like level of product customization and orientation (Athaide and Zhang, 2011), customers need delectableness and heterogeneity said by (Cui and Wu, 2016), and innovative curiosity and disturbance (Carbonell, et al. 2009) confronting the project; others stress the qualities and characteristics of customers, such as customer knowledge and information (Athaide and Zhang, 2011), lead customer status (Mahr, et al. 2014), and relationship with the company (Athaide and Zhang, 2011; Mahr, et al. 2014). Several ongoing researches have begun to examine the firm attributes, for example, development capacities (Rubera, et al. 2016), advancement-oriented techniques (Maria Stock, et al. 2017), focus on market exploration and misuse, key adaptability, and inter useful coordination (Cui and $\mathrm{Wu}, 2016$ ). Two researchers analyzed how individual mangers' credits, for example, innovativeness and proactive (Bartl, et al. 2012) and leadership and authority style (Maria Stock, et al. 2017) may impact their receptiveness to embrace RCMD This micro point of view offers an exceptional way to understanding firms' choices with respect to RCMD.

Likewise, two researches considered elements related to the management of RCMD project, including the level of formal control Customers have over NPD and strategy value evaluation to appraise the estimation of customer cooperation. These studies can offer insights on the most proficient method to manage RCMD. RCMD antecedents from the company's point of view can help clarify what kinds of tasks or firms are bound to include customers in development. Such an understanding may offer knowledge on when a firm ought to embrace RCMD and what is expected to implement it. This surge of examination offers an opportunity to more and better understand the difficulties of RCMD and how firms may defeat them by creating powerful organizational cycles and capacities.

\section{Consequences of the Firm's viewpoint}

From the firm's viewpoint, studies on the consequences of RCMD stresses on the effect of RCMD on development performance. Variety of studies in this article have been given to this crucial question. In any case, the discoveries are exceptionally conflicting. A few researches discover support for a beneficial outcome of RCMD on advancement performance (Rubera, et al. 2016), though others find that RCMD doesn't directly contribute to new product predominance or sale and deals (Carbonell, et al. 2009) and may in actuality lower NPD performance. Additionally, 
evaluating overall marketing and advancement performance, studies have also analyzed the effect of RCMD on intermediate NPD results, for example, item innovativeness, product diversity, and development speed. Discoveries with respect to these results are similarly conflicting.

A few investigations exhibit that customer created products/thoughts are characterized with higher curiosity (Schreier, et al. 2012) and that RCMD can improve product inventiveness (Cui and Wu, 2016) and product diversity. others show that RCMD doesn't have any immediate impact on product development (Ramaswamy and Prahalad, 2000) and that the advantage of RCMD exists just for impersonations concerning advancement speed, a few examinations find that involving customers can accelerate advancement (Carbonell, et al. 2009), others show that RCMD increase the time and cost of development (Von Hippel and Katz, 2002). Likewise, while a few researches find that customer produced ideas display lower achievability, others demonstrate that RCMD improve specialized quality (Carbonell, et al. 2009) and doesn't prompt lower organizational fit. Intermediate results, for example, relationship fulfillment (Athaide and Zhang, 2011) and learning (Mahr, et al. 2014; Gemser and Perks, 2015) are also analyzed, but without conclusive findings.

\section{Research Methods}

This article is a cumulative literature review of 21 empirical articles and researches on the theme "role of customer in marketing and development". It is very hard to keep up with state-of-the-art and to be at the forefront of research, as well as to assess the collective evidence in a particular area of marketing research. This is why the literature review of 21 articles are more relevant than ever which provide a comprehensive detail and information about the topic. Traditional literature reviews often lack thoroughness and rigor and are conducted ad hoc, rather than following a specific methodology. Therefore, questions can be raised about the quality and trustworthiness of review of these 21 articles. It is Important to understand for placing research findings in context, interpreting the validity of the scientific work, and ascribing a credibility level to the conclusions of published research. This goes beyond listing the magnitude and direction of random and systematic errors and validity problems.

In combining the researches for this review article, we chose 21 empirical articles that are distributed in various journals in the field of development and marketing (Journal of the Marketing Research, Journal of the Product Innovation Management, Marketing Science, Management Science, Journal of Academy of Marketing Science and Journal of Marketing) from 2000 to 2017. The keywords of this article included general terms that point out to role of customer in marketing and development (customer investment, customer contribution, customer commitment, customer strengthening, Integration of customers, client inclusion, co-creation, co-advancement and synergistic item improvement, and customer development) and particular strategies utilized in this article (lead customer, publicly supporting, competition thought, customer tool boxes, customer network, and customer plan).

\section{Samples for Articles}

While there are plenty of researches on customer value co-creation in the marketing advertising literatures, this review focused on customer advancement related investigations only. After the research, the authors collected the samples from 21 leading articles in customer involvement and marketing to ensure that these articles are relevant to their work. The 21 articles comprising of 19 qualitative researches, 1 case study and 1 quantitative meta-analysis (Chang and Taylor, 2016; Gemser and Perks 2015; Hoyer, et al. 2010).

Table 1. Sampling Method for Articles

\begin{tabular}{cccc}
\hline Number of articles & Qualitative Research & Quantitative Research & Case Study Research \\
\hline 21 & 19 & 1 & 1 \\
\hline
\end{tabular}

Source: Secondary data processed 


\section{Unit of Analysis}

In previous empirical studies two units of analysis has been conducted which are (individual unit and the firm unit) these unit of analysis includes two viewpoints: The customers' viewpoint and the firms' viewpoint.

- The customers' viewpoint that consider RCMD issues from customer perspectives and stresses on characteristics and practices of customers in marketing and development.

- The company's viewpoint that looks at RCMD issues from firms' perspectives and analyzes company's action of including customers and how RCMD may influence advancement performance.

\section{Results and Discussion}

\section{Research Variability from RCMD}

Customers help companies generate profits, the economic fuel needed to run a thriving business. By buying corporate products and services, clients reward a company for its operating prowess, setting businesses with lackluster goods apart from segments with performing products. Few research considered mediation impacts where customer cooperation in marketing and development impacts information sharing, NPD coordination, and relationship-particular investment, which then contribute to product performance and execution (Balka, et al. 2014).

Various investigations have considered moderators that may improve or hinder the impact of RCMD on development performance, including NPD project qualities, such as Product innovativeness, explorative or exploitative undertaking (Fuchs, et al. 2013), learning approach and Product presentation timing, venture leader experience and work group support, contribution of outside firm-related factors, such as, abilities and key direction (Chang and Taylor, 2016), and industry setting, like goods and services (Maria Stock, et al. 2017).

As the quantity of studies on customers' role in marketing keeps on expanding, mix of various conceptualizations is vital for additional advancement in this regard. Besides, different empirical settings may impact the connections found in these researches. For instance, a B-to-C publicly supporting setting and a B-to-B Product co-advancement setting are significantly different and may include distinctive development components. Studies that look at supporting contrast customer created ideas with professional produced ideas, while researches in the co-advancement settings evaluate market performance of end products. These two kinds of studies offer discoveries that may not be comparable. There are great differences in the idea used to investigate customer's role some of the concept are not obviously characterized or characterized in various manners as per their specific context. The operationalization of these thoughts changes extraordinarily. The absence of a connected or related conceptualization is risky in light of the fact that it may lead to shifting operationalization of the construct, make it hard to accommodate opposing discoveries, and eventually make difficulties for hypothesis testing and knowledge accumulation in this domain. Besides, compared to the general level of customers' role in marketing and promoting, the categorization of it gives more potential to hypothetical improvement that associates customers' various roles to organizational and vital changes that organizations need to perform it. However, because of the rising idea of the literature, not many empirical examinations aside from (Cui and Wu, 2016) have received the conceptualization of various roles of customer in marketing and improvement structures in testing relationships including this concept, for example, its antecedents and consequences. Although the heterogeneity of conceptualizations and approaches is an impression of a rising literature, it likewise points out to varying research tools received by researchers of various foundations and an absence of intelligible hypothetical advancement in the field.

\section{Mediator Effect}

Few research considered mediation impacts where customer cooperation in marketing and development impacts information sharing, NPD coordination, and relationship-particular 
investment, which then contribute to product performance and execution (Balka, et al. 2014). The inconsistent discoveries could be because of the absence of consideration of more complex connections, for example, curvilinear impacts and mediation impacts. Among the investigations assessed, just one inspected curvilinear impacts and discovered transformed connections between open development and product creativity/achievement (Fuchs, et al. 2013). Few researches (Carbonell, et al. 2009; Mahr, et al. 2014) analyzed the interrelationships among various development results, which may likewise help understand the components through which RCMD contributes to development performance.

\section{Moderator Effect}

Various investigations have considered moderators that may improve or hinder the impact of RCMD on development performance, including NPD project qualities, such as Product innovativeness, explorative or exploitative undertaking (Fuchs, et al. 2013), learning approach (Cui and Wu, 2016), Product presentation timing (Jensen, et al. 2014), venture leader experience and work group support (Carbonell, et al. 2009), contribution of outside firm-related factors, such as, abilities (Cui and Wu, 2016; Rubera, et al. 2016) and key direction (Chang and Taylor, 2016), and industry setting, like goods and services (Maria Stock, et al. 2017). From the viewpoints of B-to-B interorganizational connections, analyzed the Moderating role of customer network availability, measure relationship, and cycle complexity.

These unexpected impacts offer helpful experiences on when RCMD is useful and feature the complex connection among RCMD and development performance. Many researchers have brought up both the advantages and disadvantages (Hoyer, et al. 2010; Nambisan and Baron, 2009). Yet, to empirically analyze these different sides of RCMD, research needs to distinguish the correct moderator that can impact how these different sides play out. Rather than asking if RCMD is helpful or not, researches need to investigate explicit elements of RCMD and inspect how these elements impact development results. For instance, (Mahr, et al. 2014) inspected the idea of customer co-created knowledge and information in the terms of cost, significance, and curiosity, which catch detailed perspectives that are more useful than the general level of RCMD. Other constructs that can capture more explicit parts of RCMD would offer a more refined understanding of the effect of customer contribution on development execution and performance. A closer assessment of mediation impacts would also be helpful for understanding explicit systems through which RCMD influences marketing and development performance.

This paper uncovers various perceptions of the literature. So the detailed of discussion parts are following: Firstly, research on RCMD comprises of different streams of literature that follow various conventions and remain very detached from one another. It is likewise clear in the differentiating hypothetical viewpoints received in these investigations. One stream of examination follows the behavioral approach to focus on customer practices in B-to-C settings, though another flood of exploration takes the organization's viewpoint to inspect firms' choices of including customers in development and how such activities impact marketing and development performance. Neither stream of studies inspects the variables that inspire organizational customers to participate in RCMD and the effect of RCMD on their presentation these diverse subareas will in general focus on issues that are explicit to their domains, nor they rarely obtain from or coordinate with different subareas.

Secondly, in spite of the fact that exploration from the customer's point of view and that from the company's viewpoint show up very disengaged from one another, we see some common themes between these two streams of research that might be of interests for future exploration in this regard. For instance, customer knowledge and experience has all seems to be vital for RCMD from the two points of view (Athaide and Zhang, 2011). Learning capacities of a customer (Nambisan and Baron, 2009) and of a firm (Cui and Wu, 2016; Rubera, et al. 2016) have both been discovered to be exceptionally important for RCMD. These common factors between the two surges of studies show that various streams of RCMD research may profit by coordinating the discoveries from other viewpoints. 
Thirdly, research taking the customer's viewpoint and that taking the firm's viewpoint differ generously. Antecedents of RCMD have been inspected widely from the customer's point of view to understand what rouses and empowers individual customers to develop, but significantly less exploration is done from the firm's viewpoint to understand what drives firms to receive RCMD and what prepares them to effectively preform it. While the outcomes of RCMD have been generally inspected to understand its effect on marketing and development performance, the discoveries are profoundly conflicting, and research is regularly restricted to a simple connection between the level of RCMD and development performance without an adequate idea of particular mediating mechanisms through which RCMD leads to successful development. Studies from the customer's viewpoint gives helpful insight on the customers' mental and psychological cycles and behaviors, however it doesn't straightforwardly address the key inquiry of how customer information sources can be converted into improved marketing and development performance. However, the two practitioners and researchers perceive the difficulties and challenges that organizations face while implementing RCMD systems, existing examination offers restricted understandings of how firms may manage RCMD.

Lastly, there is an absence of hypothetical improvement in all subareas. A lot of studies depend on the NPD literature to build up their expectations yet do not have a solid hypothetical foundation, especially a connection with existing marketing hypotheses. However, a few research embrace certain hypothetical points of view, the application of theories is not exactly precise, and hypothetical discussions often lack depth. Most examinations are empirically determined, stressing on testing connections that are explicit to a setting rather than generalizing and compiling or incorporating findings to advance existing hypotheses or to develop new theories.

\section{Implication and Conclusion}

The rapid revolutionary growth of role of the customer in marketing and development research is energizing, yet further development in this regard needs integration of different streams of studies and better and stronger hypothetical development. A connected concept of RCMD that incorporates the level of RCMD as well as the different roles of customer that can help catch the complexity of this concept and associate studies in various empirical context. A strategic point of view is truly necessary to understand the drivers and effect of RCMD on marketing and development performance, company strategy and procedure, and long or short term competitive advantage. Such a viewpoint requires coordinating empirical studies with existing marketing hypotheses, which will not just encourage hypothetical improvement on RCMD but additionally, open door for broader understanding in the field of marketing.

While we gathered all the necessary information about RCMD through this review, this article provides detailed suggestions for future researches and further studies in the domain of Role of customers in marketing and development:

1. This article suggest that future studies ought to embrace a consistent and predictable conceptualization of RCMD and restrain using wide terms, for example, co-production and co-creation from the service researches and customer commitment from social marketing that are not explicit to the development setting. In particular, we suggest that the conceptualization of (Cui and Wu, 2016), i.e., the arrangements of different types of RCMD offers a decent method to coordinate different conceptualizations in the current study as it catches various types of RCND dependent on hypothetical qualifications of customers' jobs. (Cui and Wu, 2016) give a definite correlation of various types of RCMD regarding marketing and development, level of customer connection, customers' commitment, and key duties and responsibilities and difficulties or obstacles that the firm faces. Studies and experiments may go ahead of customer practices and behaviors, like submission of idea and look at how to incorporate customer commitment with existing development frameworks, taking into account that the autonomous function of customers may create a gap between customer-designed products and firms' current practices and abilities. Studies may ask questions and do inquiries that are acceptable and applicable to various empirical settings, compare relationship and make stronger commitments to hypothetical advancement and development. 
2. The examination and review of different literature uncovered a requirement or need for a strategic point of view in RCMD research. Such a viewpoint can supplement the huge number of studies on consumers' mental or psychological and social cycles and help to understand how firms can efficiently control and manage RCMD to make an interpretation of customer contributions to effective development. This article examines this vital point of view for future examination directions along three aspects: (1) how to associate and coordinate studies from the customer's and the firm's viewpoints of RCMD. (2) How to apply existing studies to improve the hypothetical development of RCMD. (3) How to manage RCMD.

3. Future researchers should understanding the vital drivers of role of customer in marketing and development. This review on the antecedents of RCMD from the customers' and demonstrates that more examination is expected to inspect the antecedents of RCMD from the Firm's viewpoint. As an increasing number of firms adopt the practice of the procedure to effectively include customers in their development cycle, research that inspects what encourage a firm to include their customers to the best extend and what types of RCMD would be more valuable for a firm would have both hypothetical and practical implications for dealing with this difficult cycle. For instance, what components impact firms' decisions of various types of RCMD, what sources and abilities are needed for firms to effectively draw in customers in marketing and development, what kinds of vital strategy and cultural or social environment inside the firm can better backup or support RCMD. Plenty of researchers have required a more profound understanding of organizational conditions that are helpful for RCMD for example (Hoyer, et al. 2010; Mahr, et al. 2014). A superior understanding of the organizational and strategic or key drivers of RCMD can help answer these questions.

4. Future scholars and researchers need to understand the key effect of customer association in marketing and development. Another significant point for future exploration and study is to analyze the mediating instruments that help to clarify how RCMD can be converted into fruitful development. This is particularly valuable for better understanding the advantages and compromises of RCMD through its unique systems. For instance, powerful learning, advanced creativity, and organizational productivity can be significant mediators that represent various ways through which RCMD improves its development. Studies could also look at the effect of various types of RCMD and consider their effect on various NPD results, for example, imagination, effectiveness, and speed. Besides, future scholars and researchers needs to do more development performance and look at how the selection of RCMD may affect firms' general strategic and vital decisions and short or long term performance and outcomes.

5. Future Scholars and researchers need to understand the administration of customer inclusion in marketing and development. As past examination has perceived, managing RCMD can be a difficult cycle. For instance, allowing customers independence can lessen the company's power over NPD exercises and pose critical dangers for the firm (Jensen, et al. 2014); including customers in NPD requires significant administrative change (Hoyer, et al. 2010); close cooperation with customers requires coordination (Maria Stock, et al. 2017) that expands the complexity of NPD management and control (Hoyer, et al. 2010); customer created development may not be compatible with company's resources and techniques. In this manner, more exploration is expected to inspect the design of RCMD cycles and structures that can defeat these difficulties, for instance, how to adjust the level of customer independence and firm control in RCMD, and how to encourage the coordination and integration with the customers in the NPD cycle. A vital and strategic view is definitely advantageous to answer these questions.

6. Future analysts and researchers need to connect the studies from the customer's and Firm's view point. Researches from the company's viewpoint can profit by coordinating discoveries from the customer's viewpoint, for example, customers' credits, and their mental or psychological and practical or behavioral measures. Understandings of customers' inspirations and capacities to take part in development have significant implications for how firms may plan and deal with their development cycles to support customer cooperation, select the correct customers, and efficiently use customer inputs. Different mental or psychological outcomes of 
RCMD also recommend that organizations may upgrade customer support by helping customer accomplish the psychological advantages they look for. Customer reactions to take part in development are firmly identified with decisive moves that make such reactions. Precisely, by involving customers' responses and decisive actions, future studies can better analyze the efficiency of various RCMD systems and give insight on the design or plan of RCMD measures and processes.

7. Future Researchers and scholars need to understand whether RCMD can give a firm long term competitive advantage depends upon how much customer resources are not adaptable or imitable, which is not specified by the customers but by the firm's unique organizational framework to use RCMD. A related question rises that how firms can build capacities that empower them to efficiently bridle RCMD. In order to better understand RCMD capacities, researchers need to understand the authoritative and organizational routines related with RCMD that impact managers' eagerness and capacity to implement and perform RCMD (Bartl, et al. 2012).

\section{References}

Athaide, G. A., and Zhang, J. Q. (2011). The determinants of seller-buyer interactions during new product development in technology-based industrial markets. Journal of Product Innovation Management, 28(s1), 146-158.

Balka, K., Raasch, C., \& Herstatt, C. (2014). The effect of selective openness on value creation in user innovation communities. Journal of Product Innovation Management, 31(2), 392-407.

Bartl, M., Füller, J., Mühlbacher, H., \& Ernst, H. (2012). A manager's perspective on virtual customer integration for new product development. Journal of Product Innovation Management, 29(6), 1031-1046.

Carbonell, P., Rodríguez-Escudero, A. I., \& Pujari, D. (2009). Customer involvement in new service development: An examination of antecedents and outcomes. Journal of Product Innovation Management, 26(5), 536-550.

Chang, W., and Taylor, S. A. (2016). The effectiveness of customer participation in new product development: A meta-analysis. Journal of Marketing, 80(1), 47-64.

Cui, A. S., and Wu, F. (2016). Utilizing customer knowledge in innovation: antecedents and impact of customer involvement on new product performance. Journal of The Academy of Marketing Science, 44(4), 516-538.

Dahl, D. W., Fuchs, C., \& Schreier, M. (2015). Why and when consumers prefer products of userdriven firms: A social identification account. Management Science, 61(8), 1978-1988.

Franke, N., Schreier, M., \& Kaiser, U. (2010). The "I designed it myself" effect in mass customization. Management Science, 56(1), 125-140.

Franke, N., Von Hippel, E., \& Schreier, M. (2006). Finding commercially attractive user innovations: A test of lead-user theory. Journal of Product Innovation Management, 23(4), 301 315.

Fuchs, C., Prandelli, E., Schreier, M., \& Dahl, D. W. (2013). All that is users might not be gold: How labeling products as user designed backfires in the context of luxury fashion brands. Journal of Marketing, 77(5), 75-91.

Füller, J., Matzler, K., \& Hoppe, M. (2008). Brand community members as a source of innovation. Journal of Product Innovation Management, 25(6), 608-619.

Gemser, G., and Perks, H. (2015). Co-creation with customers: An evolving innovation research field. Journal of Product Innovation Management, 32(5), 660-665. 
Hoyer, W. D., Chandy, R., Dorotic, M., Krafft, M., and Singh, S. S. (2010). Consumer cocreation in new product development. Journal of Service Research, 13(3), 283-296.

Jensen, M. B., Hienerth, C., \& Lettl, C. (2014). Forecasting the commercial attractiveness of usergenerated designs using online data: An empirical study within the LEGO user community. Journal of Product Innovation Management, 31, 75-93.

Mahr, D., Lievens, A., \& Blazevic, V. (2014). The value of customer cocreated knowledge during the innovation process. Journal of Product Innovation Management, 31(3), 599-615.

Maria Stock, R., Zacharias, N. A., \& Schnellbaecher, A. (2017). How do strategy and leadership styles jointly affect co-development and its innovation outcomes?. Journal of Product Innovation Management, 34(2), 201-222.

Nambisan, S., \& Baron, R. A. (2009). Virtual customer environments: testing a model of voluntary participation in value co-creation activities. Journal of Product Innovation Management, 26(4), 388-406.

Ramaswamy, V., and Prahalad, C.K. (2000). Co-opting customer competence. United States: Harvard Business Review.

Rubera, G., Chandrasekaran, D., \& Ordanini, A. (2016). Open innovation, product portfolio innovativeness and firm performance: the dual role of new product development capabilities. Journal of the Academy of Marketing Science, 44(2), 166-184.

Schreier, M., Fuchs, C., \& Dahl, D. W. (2012). The innovation effect of user design: Exploring consumers' innovation perceptions of firms selling products designed by users. Journal of Marketing, 76(5), 18-32.

Von Hippel, E., and Katz, R. (2002). Shifting innovation to users via toolkits. Management Science, 48(7), 821-833. 